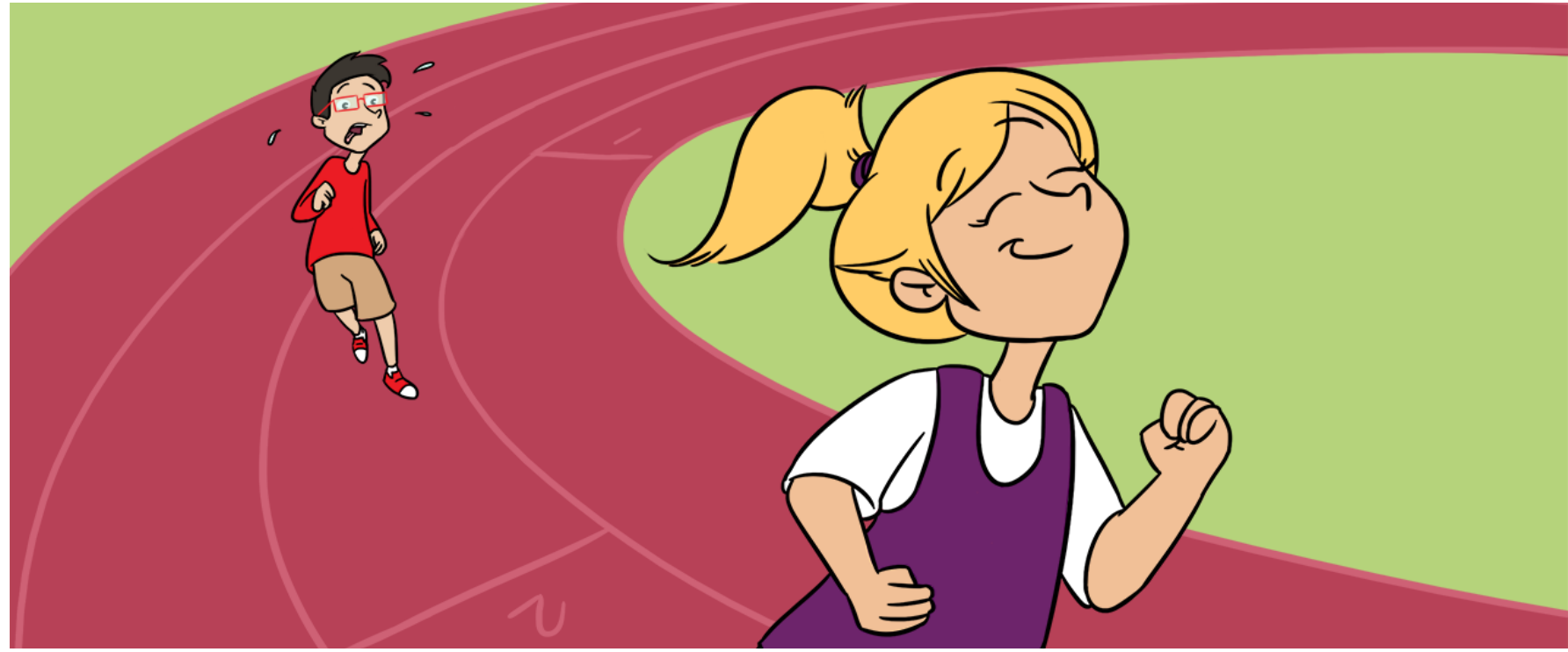

\title{
WHAT IS THE BEST WAY TO TRAIN TO BECOME A STAR ENDURANCE ATHLETE?
}

Thomas Leonhard Stöggl*

Department of Sport Science and Kinesiology, University of Salzburg, Salzburg, Austria

REVIEWED BY:

ANNIE

AGE: 14
This article deals with the best way to train to maximize performance in endurance sports. Most scientific studies show that successful endurance athletes use a training concept with a great proportion of training with low exercise intensity (Zone 1-e.g., running with low to moderate speed over longer time) combined with training sessions using very high exercise intensities (Zone 3-e.g., interval training, repeated sprints) and almost no training in the moderate-intensity zone (Zone 2). This is called polarized training. Athletes generally start their training year with a Zone 1-oriented training concept. In the months before the first competitions start, they switch to a training concept with high proportion of Zone 1, and an increased amount of Zone 2 and Zone 3 training. Within the competition phase, they generally use polarized training. The article will also discuss the problems scientists face when studying how elite endurance athletes train and will introduce some questions that still do not have solid answers. 
${ }^{1}$ Please note that all references for the individual statements in this article can be found in our previous review on this topic, Stöggl and Sperlich [1].

\section{INTRODUCTION}

Endurance is when an athlete can do a certain physical exercise over a long-time period without getting exhausted. Are you already well trained in endurance exercise, or do you have the feeling that some of your friends are doing much better when it comes to endurance? How can you improve your endurance level to catch up with your endurance-gifted friends? Maybe your great ambition in sports is to become a famous elite endurance athlete, with heroic targets like beating the $2 \mathrm{~h}$ in a marathon, winning the Tour de France, or earning a gold medal in cross-country skiing. After you have decided on your future goals, the next question becomes how to train the right way to achieve these goals. Should you train for short periods of time with high intensity, or just go easy and train for a longer time, or choose an intensity that is somewhere in the middle? Or is it best to just mix all intensity zones together, somehow? You might also ask yourself how often and how long you need to train in total-per day, per week, per month, and across the year. As you can see by reading these questions, there are many things to consider before starting your "perfect" training strategy. The basic idea of this article is to provide you with information on how successful athletes in endurance sports train and which training models lead to greater success. We will also discuss some unanswered questions about training - the things we are not yet sure about, or things that are not scientifically proven. ${ }^{1}$

\section{WHY IS IT DIFFICULT TO STUDY ELITE ENDURANCE ATHLETES?}

There are many studies about the effects of different training methods on average athletes; however, there is hardly any data on the most successful endurance athletes. Why that is? Why do not elite athletes want to get involved in scientific experiments?

Elite athletes have a lot at stake when it comes to their training. Many of them are professional athletes, meaning that they make their living from competing. The fact is that the outcome of an experiment is not clear from the beginning. So, if athletes agree to take part in an experiment that changes their method of training, they have no idea what the experimental training method will do to their level of performance. Maybe the new method will not change their performance, maybe it will improve performance, but maybe it will actually decrease performance. So there is always a risk for the athlete. Also, for scientific experiments to be valid, they need to be standardized and controlled in many ways, meaning that athletes in an experiment might have to change their diets or daily activities, and they might not want to do that, because it could interfere with their training. This becomes more difficult the longer the training experiment lasts. 
ZONE 1, ZONE 2, ZONE 3

Training intensity referring to low (e.g., $70 \%$ maximal heart rate), moderate (80\%), and high intensity (90-100\%).
To overcome these problems, instead of real experiments, so-called retrospective studies are often done to understand the best possible method of training. In these retrospective studies, scientists just keep track of how the best athletes are training, without telling them how they should train.

\section{HOW DO WE MEASURE THE INTENSITY OF TRAINING?}

Another challenge is how to measure how much training is done (=training volume) and the intensity of that training (=training intensity). Based on certain measurements like for instance heart rate, the exercise intensity can be split up into different zones. In this article, we will focus on a three-zone model, where we call low-intensity Zone 1, medium intensity Zone 2, and high-intensity Zone 3. There are a few important things to know about using these three zones to describe endurance training:

- When training in Zone 1, an athlete can exercise for hours (maybe up to $24 \mathrm{~h}$ ); however, in Zone 3, the athlete would probably get tired after 15-30 min. That means that people usually spend the most time training in Zone 1 (Figure 1).

- The amount of time spent in each zone depends on the type of exercise being performed. For instance, a person could cycle for $5 \mathrm{~h}$ in Zone 1, but running for the same amount of time would be difficult, because running is harder on the body than cycling. This might be one reason why runners train for considerably less time than cyclists and rowers (500-700 h/year for runners versus up to $1,400 \mathrm{~h}$ /year for cyclists/rowers).

- It is complicated to report training, because there are lots of different methods for measuring how long or how hard athletes train. The different methods of measurement can lead to substantially different results. All of the methods have strengths and weaknesses. One of the most common methods is to figure out the percentage of time spent in each intensity zone, based on heart rate values - the heart rate time-in-zone approach. One problem with this method is that the high-intensity zone (Zone 3 ) is often documented too short. This is based on that the heart does not adapt so quickly to changes in the exercise intensity (for instance, when making a high-intensity Zone 3 run, it often takes 1 min or longer that the heart rate gets so high that it fits to Zone 3). Another common method is called the session goal approach. This approach is based on the main goal of the training session and its intensity zone-irrespective of warm-up, cool-down, or breaks in between intervals. So, if the athletes main goal for the workout is a Zone 2 interval training (e.g., 15 min Zone 1 warm-up followed by the main part of the training: four times $5 \mathrm{~min}$ in Zone 2, with $3 \mathrm{~min}$ Zone 1 active rest between the intervals and a $15 \mathrm{~min}$ Zone 1 cool-down) that workout would be classified as a Zone 2 workout. This, even though the time in Zone 1 would be about 40 min being the double of Zone 2 duration. This can become difficult to figure out, though. For example, if an athlete does a 2-h Zone 1 training, including $7 \times 30 \mathrm{~s}$ 


\section{FIGURE 1}

Common training durations within a certain intensity zone.

Zone 1, low intensity (around $70 \%$ of the maximal heart rate); Zone 2 , moderate intensity (around $80-90 \%$ of the maximal heart rate); Zone 3 , high intensity (heart rate $>90 \%$ of maximal heart rate).

\section{FIGURE 2}

A. An example of a 1-week training plan. The bars show the duration of every single training in hours. The colors represent the exercise intensity according to Zone 1 = green, Zone 2 = yellow, and Zone $3=$ red. B. The total amount of training in $\mathrm{h}$ :min in Zone 1, Zone 2, and Zone 3 of the training week shown in panel A. The training can be analyzed according to either the heart rate approach or the session goal approach. C. Using the heart rate time-in-zone method, you can see that based on the heart rate recordings $82 \%$ of the weekly training was performed in Zone 1, 11\% in Zone 2, and only $7 \%$ in Zone 3. D. Using the session goal method, you can see that the same training resulted in only 40\% Zone 1, 20\% Zone 2, and $40 \%$ Zone 3 training. So, based on the method, totally different numbers in each zone will be calculated.

TID

Training intensity distribution.
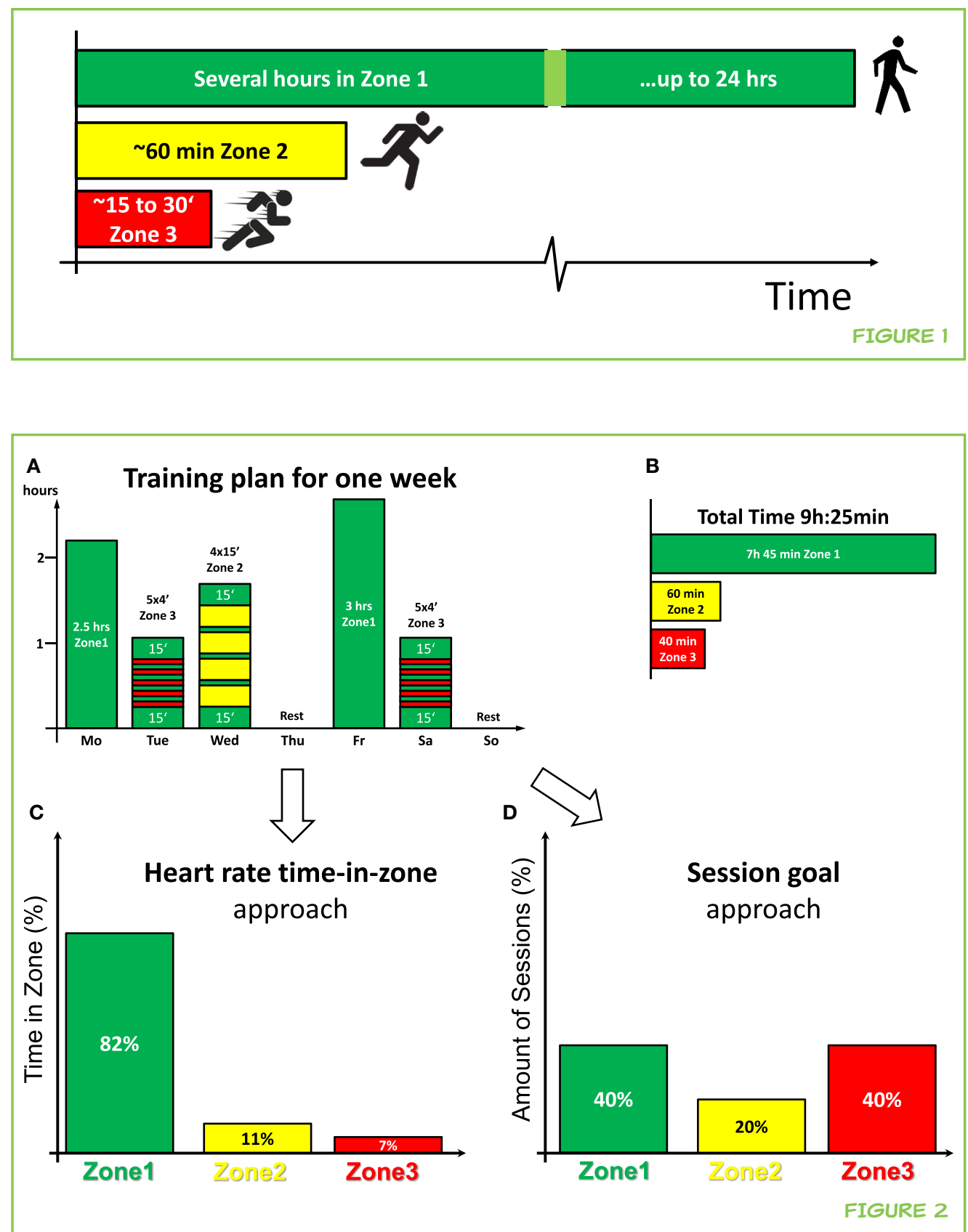

full-speed sprints every $10 \mathrm{~min}$ (Zone 3), is the entire session Zone 1 or Zone 3 or a mix? These different methods are shown in Figure 2.

\section{SO, HOW DO ENDURANCE ATHLETES ACTUALLY TRAIN?}

To explain the training methods athletes use, we use the term training intensity distribution (TID), which means how an athlete distributes their training across the three intensity zones. Several TIDs are commonly used by athletes and have been studied by scientists. Using the three-zone intensity model we have described, the following TID patterns are possible (Figure 3). 
FIGURE 3

Illustration of different training methods or training intensity distributions (TIDs), in endurance sports. A. If the major proportion of the training is low intensity (Zone 1) and typically of longer duration (volume), it is called a high-volume low-intensity training (HVLIT); B. High-intensity training $(H I T)$ has a big focus on Zone 3 and only a minor focus on Zones 1 and 2; C. Pyramidal TID looks like a pyramid, with the largest proportion of training in Zone 1, followed by a decreasing proportion in Zones 2 and 3; D. Inverse pyramidal training is just the opposite, with the largest proportion of the training in Zone 3 , followed by Zone 2 and Zone 1; E. When the main focus is on Zone 2, this is called threshold training;

F. Polarized training has the main focus on Zones 1 and 3 , with almost no training in Zone 2-the main training is performed in the two extremes (or poles) of the intensity scale; G. Inverse polarized TID has a greater amount of Zone 3 training compared with Zone 1; and $\mathbf{H}$. If all three zones are trained in equal proportion it is called uniform, even, or equal TID.

\section{PYRAMIDAL}

A TID that looks like a pyramid with greatest amount of Zone 1 followed by Zone 2 and Zone 3 training.

\section{HVLIT}

High-volume low-intensity training; a TID with a major proportion of the training in Zone 1.

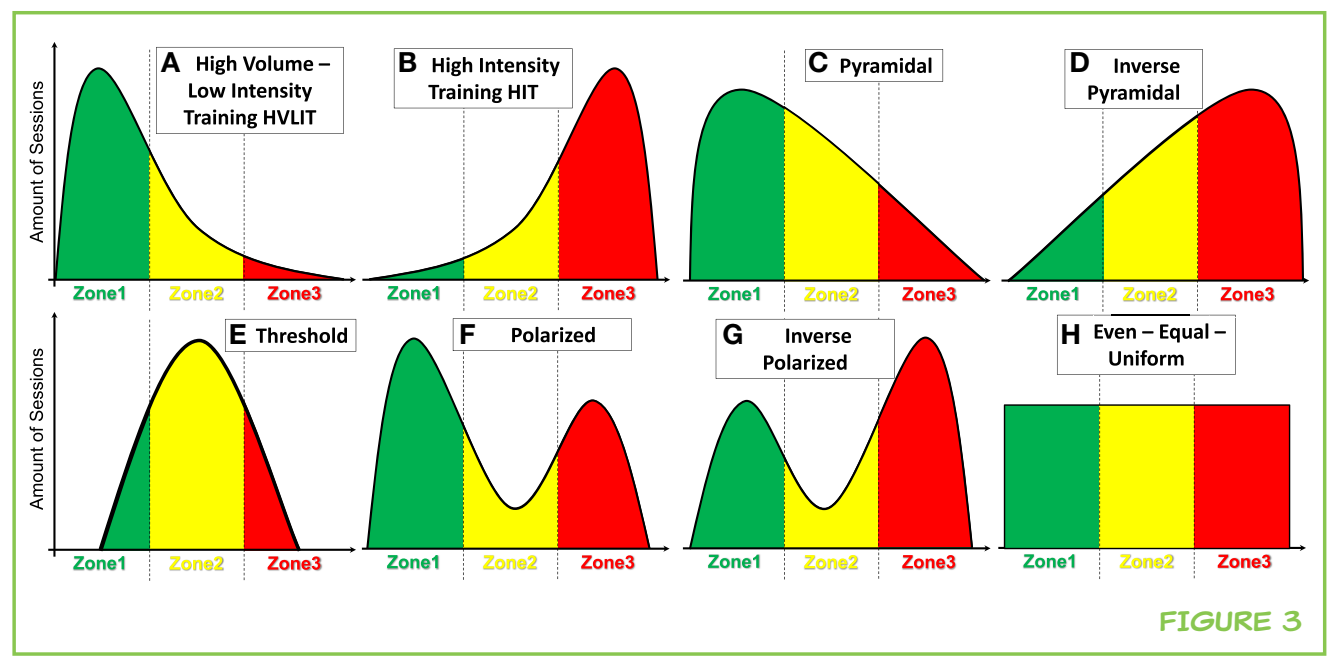

HOW DO ELITE ATHLETES TRAIN THROUGHOUT THE YEAR?

There is a lot of variation in the number of hours per year that endurance athletes train and the way they train. For instance, when comparing the annual training hours in Olympic and World Champion endurance athletes in crosscountry skiing and biathlon, the range was between 622 and $942 \mathrm{~h} /$ year, representing a $50 \%$ difference [2]. Scientists have found that these athletes train up to 500 times per year, in about 8-14 workouts a week. This means more than one workout a day on some days! Most of this training is in Zone 1 (70-94\%), with less in Zone $2(4-22 \%)$ and Zone $3(2-11 \%)$, in either a pyramidal or polarized TID.

There is also a lot of variation in the way endurance athletes space out their training over the course of the year. But, there seems to be a pattern across the training season, from a focus on high-volume, low-intensity training (HVLIT) during the preparation phase (the 5-6 months training period at the start of the training year), toward a pyramidal TID during the precompetition period (the 1-2 months before the first competitions start), and a polarized TID during the competition phase (the 3-5 months where the main competitions take place) (Figure 4). The monthly frequency of Zone 3 sessions (high intensity) increases from preparation phase to the pre-competition phase and remains unchanged throughout the competition period, while the amount of Zone 1 decreases.

\section{WHAT DO THE SCIENTIFIC STUDIES SHOW?}

In general, the experimental studies have shown that all of the different training methods led to improvements in the athletes' performance. However, in almost every study, the polarized group achieved the greatest improvements. The majority of the experimental studies looked at the training behaviors of recreational or amateur athletes. However, in one of our recent studies on well-trained endurance athletes, we also found that the polarized TID resulted in the greatest improvements in endurance performance, followed 
FIGURE 4

Training intensity distribution (TID) during certain phases of a training year.

For instance, in crosscountry skiing, the preparation phase starts around May and ends in August, followed by the pre-competition or specific preparation phase, from September to November, and the competition phase from December until March. You can see that the TID changes from a highvolume low intensity (HVLIT) oriented TID in the preparation phase, toward a pyramidal TID in the pre-competition phase and a polarized TID during the competition phase.

\section{PREPARATION \\ PHASE}

The first month within a training year; usually this period starts some weeks after the termination of the competition phase.

PRE-COMPETITION PHASE

Defined as the 1-2 months period before the first competitions start.

\section{COMPETITION \\ PHASE}

The period where the main competitions take place.

\section{HIT}

High-intensity training; greatest amount of training is within Zone 3.

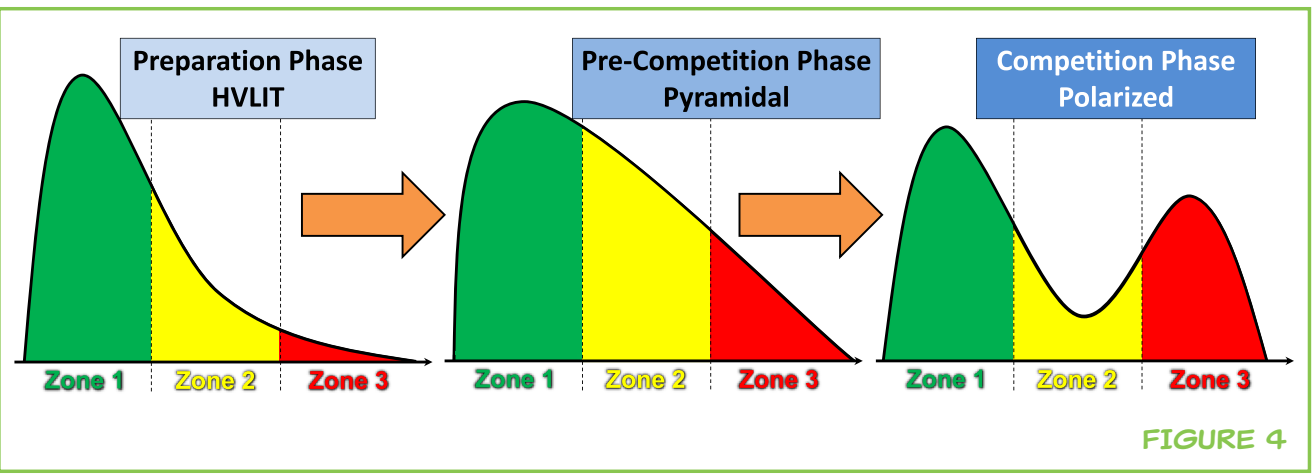

by high-intensity training (HIT), while a HVLIT or Threshold TID was not effective [3].

\section{WHY DOES A POLARIZED TID APPEAR TO BE THE BEST?}

One explanation of why a polarized TID works best as a training method could have to do with the way the body gets energy during the single training workouts. In general, the body can produce energy from either carbohydrates or fats. Training in Zone 1 consumes about equal amounts of carbohydrates and fat (50 versus 50\%), Zone 2 places greater demands on carbohydrates than fat (approximately 75 versus 25\%), and Zone 3 almost entirely relies on carbohydrates. These numbers can be used to calculate how much energy is used in total and how much is spent with respect to energy from fat or carbohydrates with different types of TIDs. For instance, when a polarized TID is used, an athlete can train longer and spend more time in Zone 3 with about the same total energy needed but substantially lower use of carbohydrates when compared with a TID with lot of Zone 2 training (e.g., the Threshold TID).

Another suggestion as to why a polarized TID works best is that the steady switch between Zones 1 and 3 keeps the athletes from getting bored. It is also possible that the intense training in Zone 3 does less damage to the athletes' bodies when there is some variation in the intensity of the training-they get a "break" when they train in Zone 1.

It is also possible that low intensities are more helpful for the muscles while high intensities are more important for the heart and the nervous system. For example, since the muscles contract at a higher speed in Zone 3 training, more of the faster muscle fiber types are used and this increases the "fitness" of the muscle for high-intensity work. This probably does not happen when training is only in Zone 1.

There is another theory that, with polarized training, you "train like a caveman." Looking back at how our ancestors might have lived, they either performed Zone 1 activities (like roaming from one place to another to find water or areas with more food) or they needed to perform Zone 3 activities when 
POLARIZED

TRAINING

A TID that has the main focus on Zone 1 and Zone 3 with almost no training in Zone 2. hunting or being hunted (fight or flight). There was not really much of a need for them to spend a lot of time in Zone 2.

\section{HOW MUCH HIT IS NEEDED AND WHEN IS IT TOO MUCH?}

Several studies have shown that HIT can help to improve the performance of endurance athletes. The advantage to the HIT method is that much less training time is needed, and some studies showed that HIT was more enjoyable for the athletes than HVLIT training. The data show that approximately two HIT sessions per week may increase performance without being too stressful on the body. On the other hand, the data showed that too many HIT sessions over a longer period might not help performance and might actually lead to overtraining, which can result in a performance decrease and long-term symptoms of exhaustion $[3,4]$.

\section{WHY DO ELITE ENDURANCE ATHLETES TRAIN SO MUCH AT LOW INTENSITY?}

As we mentioned earlier, elite endurance athletes spend the majority of their time (70-94\%) training in Zone 1. We still do not understand why a successful endurance athlete needs to spend so much time training at this level. As we said earlier, the studies have shown that with HIT, athletes get the same or even greater improvements in performance than they do from HVLIT, but in a much shorter time. Some other studies demonstrated that a continuing to increase Zone 1 training will eventually no longer improve endurance performance and might even negatively affect an athlete's mood, if too much time is spent training. So, we do not really know why so much low-intensity training works, but it is possible that on the molecular level, both Zone 1 and Zone 3 training lead to the same positive changes in the athlete's body; they just use a different molecular pathway [5].

\section{CONCLUSION AND SUMMARY}

In summary, the current scientific research proposes that a pyramidal or polarized TID with a substantial amount of Zone 1 training combined with some Zone 3 training is the best way to maximize endurance performance. Pure focus on Zone 1 or Zone 2 training does not work as well as polarized or pyramidal TIDs. But, there are still several unanswered questions. For instance, the long-term effects of some TIDs (like inverse polarized or HIT) on elite endurance athletes are still not totally understood. The choice of the TID also depends on the amount of time that is available for the athlete to train. For example, a professional athlete has much more time to train than someone who has a full-time job. So, in some cases, when the athlete is very busy, the choice of a polarized TID with a large training volume might not be possible and a more HIT-oriented training might work better for the athlete. Last, the reason why endurance athletes train so much at a low-intensity cannot 
be clearly explained, based on current scientific knowledge. So, even though we know a lot about how athletes train, it is still not possible to identify the "best" TID, and future experiments over longer periods of time will have to be designed to answer this question.

\section{ACKNOWLEDGMENTS}

I would like to thank Donna Kennedy, Nicola Nightingale, Julia Stöggl, and Roland Stöggl for their "adult input," and Benjamin Moser, Felix Bleier, Felix Kappelsberger, Georg Gleirscher, Gotthard Gleirscher, Julia Pfennich, Lukas Riedlsperger, Sophie Nightingale, and Patrick Duci for their "youth input" in pre-reviewing and commenting the article.

\section{ORIGINAL SOURCE ARTICLE}

Stöggl, T. L., and Sperlich, B. 2015. The training intensity distribution among welltrained and elite endurance athletes. Front. Physiol. 6:295. doi:10.3389/ fphys.2015.00295

\section{REFERENCES}

1. Stöggl, T. L., and Sperlich, B. 2015. The training intensity distribution among well-trained and elite endurance athletes. Front. Physiol. 6:295. doi:10.3389/ fphys.2015.00295

2. Tonnessen, E., Sylta, O., Haugen, T. A., Hem, E., Svendsen, I. S., and Seiler, K. S. 2014. The road to gold: training and peaking characteristics in the year prior to a gold medal endurance performance. PLOS ONE 9:e101796. doi:10.1371/journal. pone.0101796

3. Stöggl, T., and Sperlich, B. 2014. Polarized training has greater impact on key endurance variables than threshold, high intensity, or high volume training. Front. Physiol. 5:33. doi:10.3389/fphys.2014.00033

4. Billat, V. L., Flechet, B., Petit, B., Muriaux, G., and Koralsztein, J. P. 1999. Interval training at VO2max: effects on aerobic performance and overtraining markers. Med. Sci. Sports Exerc. 31, 156-163. doi:10.1097/00005768-199901000-00024

5. Laursen, P. B. 2010. Training for intense exercise performance: high-intensity or high-volume training? Scand. J. Med. Sci. Sports 20(Suppl. 2), 1-10. doi:10.1111/j.1600-0838.2010.01184.x

SUBMITTED: 11 September 2017; ACCEPTED: 28 March 2018;

PUBLISHED ONLINE: 14 May 2018.

EDITED BY: Tansy C. Hammarton, University of Glasgow, United Kingdom 
CITATION: Stöggl TL (2018) What Is the Best Way to Train to Become a Star Endurance Athlete? Front. Young Minds 6:17. doi:10.3389/frym.2018.00017

CONFLICT OF INTEREST STATEMENT: The author declares that the research was conducted in the absence of any commercial or financial relationships that could be construed as a potential conflict of interest.

COPYRIGHT (C) 2018 Stöggl. This is an open-access article distributed under the terms of the Creative Commons Attribution License (CC BY). The use, distribution or reproduction in other forums is permitted, provided the original author(s) and the copyright owner are credited and that the original publication in this journal is cited, in accordance with accepted academic practice. No use, distribution or reproduction is permitted which does not comply with these terms.

\section{REVIEWED BY}

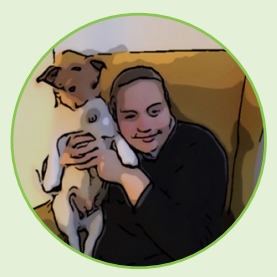

\section{ANNIE, AGE: 14}

I am interested in current affairs and I love to read novels. I like music and spending time with my friends. My favorite subjects at school are biology and geography. I love my two cats and my dog.

\section{AUTHOR}

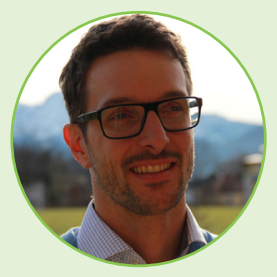

\section{THOMAS LEONHARD STÖGGL}

Thomas Leonhard Stöggl studied sport science and mathematics and loves all kind of endurance sports. During his time as student and even when starting working at university for his $\mathrm{PhD}$ and professorship, he was elite athlete in cross-country skiing and inline-speed skating and achieved 15 times the National Champion Title. His main research focus is the integrative biomechanical and physiological analysis of different types of exercise, the acute and chronic effects of different training regimes in elite athletes (especially when it comes to endurance disciplines), and the development and application of sensor technology (Wearable) in different settings during sport and exercise. *thomas.stoeggl@sbg.ac.at 